\title{
Pengembangan Instrumen Tes Passing Bolavoli Berbasis Digital
}

\author{
Suriadi, Rahma Dewi, Basyaruddin Daulay \\ Fakultas Ilmu Keolahragaan, Universitas Negeri Medan \\ suriadi2106@gmail.com,rahmadewi@unimed.ac.id,Badayfik@gmail.com
}

\begin{abstract}
Abstrak: Penelitian ini bertujuan untuk mengembangkan instrument tes passing atas dan passing bawah bolavoli. Populasi dalam penelitian ini adalah seluruh atlet di club TVRI, club PBV Mulia dan club Johar. Bentuk yang telah dibuat terlebih dahulu divalidasi orang beberapa ahli di bidangnya. Alat ini berupa adaptasi dari instrument tes sebelumnya yang masih merupakan dinding dengan diameter 1,5 x1,5 meter dengan ketinggian sesuai dengan kebutuhan tes yang akan dilakukan, menjadi bentuk portable yang dapat digunakan kapanpun dan dimanapun dengan material yang keras menyerupai dinding sehingga daya pantul bola tidak berkurang dan dilengkapi dengan sensor sehingga penghitungan menjadi lebih mudah dan akurat. Uji kelompok kecil melibatkan 20 orang atlet dari club TVRI dan uji coba kelompok besar melibatkan 30 orang atlet dari club Johar dan club Mulia. Hasil dari validasi ahli dalam ujicoba kelompok kecil bahwa dapat digunakan dimana rata-rata persentase validitasnya adalah 90,96\%. Hasil dari validasi ahli dalam ujicoba kelompok besar bahwa dapat digunakan dimana rata-rata persentase validitasnya adalah 95,33\%. Dapat disimpulkan alat tes kemampuan passing atas dan passing bawah bolavoli berbasis digital ini dapat layak atau dapat digunakan.
\end{abstract}

Kata Kunci: Instrumen, Passing bolavoli

\section{Development of Digital-Based Volleyball Passing Test Instruments}

Abstract: This study aims to develop a test instrument for passing over and under passing volleyball. The population in this study were all athletes in the TVRI club, PBV Mulia club, and Johar club. Forms that have been made are first validated by 1 expert in the field of sports, 1 volleyball coach and 1 electronic expert from the University who has a competent background in their respective fields. This tool is in the form of an adaptation of the previous test instrument which is still a wall with a diameter of $1.5 x 1.5$ meters with a height in accordance with the needs of the test to be carried out, becoming a portable form that can be used anytime and anywhere with hard material resembling a wall so that the reflectivity of the ball is not reduced and equipped with sensors so that calculations are easier and more accurate. The small group test involved 20 athletes from the TVRI club and the large group trial involved 30 athletes from the Johar and Mulia clubs. The results of expert validation in small group trials that can be used where the average percentage of validity is $90,96 \%$. The results of expert validation in large group trials that can be used where the average percentage of validity is 95,33\%. It can be concluded that the test tool for the ability to pass up and pass under digital volleyball can be feasible or can be used.

Keywords: Instrument, Volleyball passing,

\section{PENDAHULUAN}

Permainan bolavoli termasuk jenis permainan yang memerlukan latihan yang teratur dan terarah karena permainan bolavoli mengandung berbagai macam unsur gerak. Teknik dasar dalam permainan bolavoli adalah suatu proses melahirkan keaktifan jasmani dan pembuktian suatu praktek dengan sebaik mungkin untuk menyelesaikan tugas yang pasti dalam permainan bolavoli. 
Indonesia merupakan negara berkembang, namun Indonesia masih menjadi negara konsumen bagi alat-alat yang modern. Seharusnya Indonesia mampu menciptakan alat-alat yang dapat memiliki nilai jual. Sehingga akan mengurangi presentase sebagai Negara konsumen dari berbagai penemuan ilmu pengetahuan dan teknologi (IPTEK). Menurut Erfiyanto (dalam jurnal pendidikan kepelatihan olahraga 2016:2) seperti dalam bidang olahraga penemuan ilmu pengetahuan dan teknologi (IPTEK) yang di gunakan sangat banyak. Berdasarkan observasi di lapangan, kebanyakkan pelatih masih menggunakan alat seadanya, dan pada saat melatih, pelatih masik membantu proses latihan dengan cara memantulkan bola. Dan ada juga yang sudah menggunakan alat pantul bolavoli tetapi masih kurang efektif, dan masih diterapkan dengan cara manual.

Berdasarkan hasil observasi penelitian dan wawancara yang dilakukan kepada pengurus, atlet bolavoli dan pelatih Club TVRI, PBV. Tanjung Mulia dan Club Johar dapat ditarik kesimpulan bahwa dapat dilihat karena masih banyak atlet yang belum mampu melakukan passing bawah dan passing atas yang maksimal di karenakan tidak adanya papan pantul di club tersebut. Dari pengumpulan data yang telah dilakukan terhadap 30 orang atlet bolavoli diperoleh bahwa ada 100\% atlet yang ingin atau membutuhka papan pantul bolavoli dengan alasan agar mereka bisa bersemangat lagi dalam memainkan permainan bolavoli. Berdasarkan hasil pengamatan, wawancara dan analisis kebutuhan di atas maka dapat disimpulkan bahwa sangat perlu adanya pengembangan instrument tes passing bolavoli berbasis digital tahun 2019. Adapun faktor pendukung untuk meningkatkan kemampuan teknik salah satunya dengan menggunakan alat. Alat bisa bermacam-macam tapi yang dimaksud disini adalah alat membantu instrument tes passing baik itu passing bawah dan passing. Adapun alat yang diginakan ini adalah berupa papan pantul untuk meningkatkan latihan passing bawah dan passing atas. Hal ini di ketahui dari observasi beberapa $c l u b$ bolavoli salah satunya yaitu $c l u b$ bolavoli Johar yang mana alat yang digunakan masih berupa alat papan pantul bolavoli biasa.

Peneliti melakukan observasi pada club tersebut atlet yang berlatih di club ini adalah 30 orang yang aktif berlatih. Dari permasalahan diatas, Penulis ingin mengembangkan sebuah model rancangan alat yang memberi kemudahan serta keefisienan para atlet dan pelatih. Alat ini diharapkan supaya pelatih tidak melatih secara manual lagi. Atlet hanya memantulkan bola dan mengarahkan bola kearah alat pantul yang berbetuk digital. Alat pantul bola ini berbasis digital yang menggunakan Timer (waktu). Alat ini diharapakan supaya pelatih tidak melatih secara manual lagi. Dari pemaparan latar belakang masalah di atas maka dapat diidentifikasi masalanya adalah Modifikasi alat latihan teknik dasar passing bolavoli berbasis digital belum banyak ditemukan dan dikembangkan, Pelatih masih membantu proses latihan dengan cara melempar bola secara manual sehingga kurang afektif. Berdasarkan rumusan permasahan di atas maka penelitian ini bertujuan untuk untuk mengembangkan instrument tes passing bolavoli berbasis digital.

Produk yang akan dihasilkan melalui penelitian pengembangan ini mempunyai spesifikasi yaitu Hasil produk penelitian berupa alat teknik dasar passing bolavoli, papan pantul berbentuk persegi empat, timer (waktu), layar hasil, kaki rangka untuk menompang alat teknik dasar passing bolavoli, baut untuk mengatur ketinggian alat, Remote untuk mengontrol dan menghidupkan alat.

Dalam kamus besar bahasa Indonesia kata "pengembangan" secara etimologi yaitu berarti proses/cara, perbuatan mengembangkan. Secara istilah, kata pengembagan menunjukkan pada suatu kegiatan menghasilkan suatu alat atau cara yang baru, dimana selama kegiatan tersebut penilaian dan penyempurnaan terhadap alat atau cara tersebut terus dilakukan. Bila setelah mengalami penyempurnaan penyempurnaan akhirnya alat atau cara tersebut dipandang cukup mantap untuk digunakan seterusnya. (KBBI:103). Maya Sukmawati, dkk (dalam jurnal Studi Sosial, 2016:78) menyatakan hasil penelitian dan pengembangan sesuai dengan pendapat Sadiman, dkk (2011:78-81) yang menyatakan bahwa sebagai media pendidikan, permainan mempunyai beberapa kelebihan yaitu:

a. permainan adalah sesuatu yang menyenangkan untuk dilakukan dan sesuatu yang menghibur

b. permainan memungkinkan adanya partisipasi aktif dari siswa untuk belajar

c. permainan dapat memberikan umpan balik langsung, umpan balik yang secepatnya atas apa yang dilakukan akan memungkinkan proses belajar yang lebih efektif

d. permainan memungkinkan penerapan konsep-konsep ataupun peranan-peranan yang sebenarnya dalam masyarakat

e. permainan bersifat luwes dan 
f. permainan dapat dengan mudah dibuat dan diperbanyak oleh guru

Jadi dapat dikatakan bahwa penelitian dan pengembangan adalah suatu proses atau langkahlangkah untuk mengembangkan suatu produk baru atau menyempurnakan produk yang telah ada, yang dapat dipertanggungjawabkan. untuk membuat suatu produk baru atau mengembangkan produk yang telah ada menjadi lebih luas lagi dengan kata kunci produk tersebut diuji keefektifannya. Pengembangan bertujuan untuk menghasilkan produk berdasarkan temuan-temuan uji lapangan.

Menurut Ali Yusmar (dalam jurnal Pendidikan dan pengajaran, 2017:144) Permainan bolavoli adalah suatu permainan yang menggunakan bola untuk dipantulkan (di-volley) di udara hilir mudik di atas net (jaring), dengan maksud dapat menjatuhkan bola di dalam petak daerah lapangan lawan dalam rangka mencari kemenangan. Mem-volley atau memantulkan bola ke udara dapat mempergunakan seluruh anggota atau bagian tubuh dari ujung kaki sampai ke kepala dengan pantulan sempurna. Permainan bolavoli membutuhkan kemampuan untuk mengapresiasi bola, mencangkup arahnya, ketinggiannya, dan kecepatannya. bahwa kemampuan bermain bolavoli merupakan potensi seseorang untuk menunjukkan keahlian bermain bolavoli yang merupakan hasil dari latihan atau praktik. Kemampuan bermain voli juga merupakan kesanggupan seseorang untuk melakukan permainan bolavoli secara efektif dengan menguasai teknik-teknik dasar dalam bolavoli dan mampu bermain dengan baik.

Menurut Winarno, Dkk (2010:76) passing berarti mengumpan atau mengoper bola kepada kawan satu regu. Passing adalah usaha atau upaya seorang pemain bolavoli dengan cara menggunakan suatu teknik tertentu yang bertujuan adalah untuk mengoper bola yang di mainkan kepada teman pada seregu untuk di mainkan di lapangan sendiri. Yunus (1992) berpendapat bahwa passing adalah mengoper bola kepada teman sendiri dalam satu regu dengan suatu teknik tertntu, sebagai langkah awal untuk menyusun serangan kepada lawan. Terdapat dua macam passing yaitu passing bawah dan passing atas. Bagian berikut ini akan di kemukakan teknik melakukan passing, baik passing bawah mau pun passing atas. Passing bawah ialah cara yang dilakukan pemain untuk mengoper bola atau menerima bola dari depan badan menggunakan kedua tangan secara bersamaan. Passing atas atau disebut set up adalah usaha pemain untuk mengoper bola yang dilakukan saat bola diatas kepala menggunakan kedua tangan secara bersamaan.

Papan pantul terbuat dari papan atau triplek yang berbentuk persegi empat untuk memantulkan bola dengan menggunakan passing bawah dan passing atas dalam permainan bolavoli. Papan pantul bolavoli ini adalah sebagai alat bantu untuk melatih permainan bolavoli pada atlet pemula, baik itu passing bawah maupun passing atas.

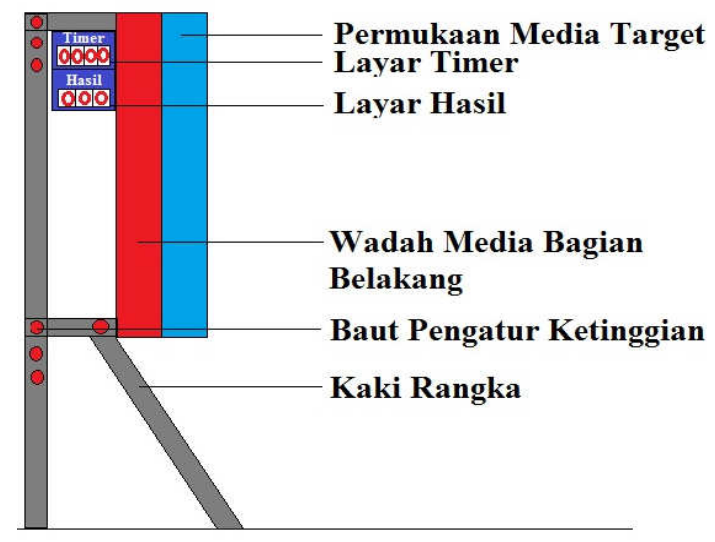

Gambar 1. Desain Alat Tampak Samping 


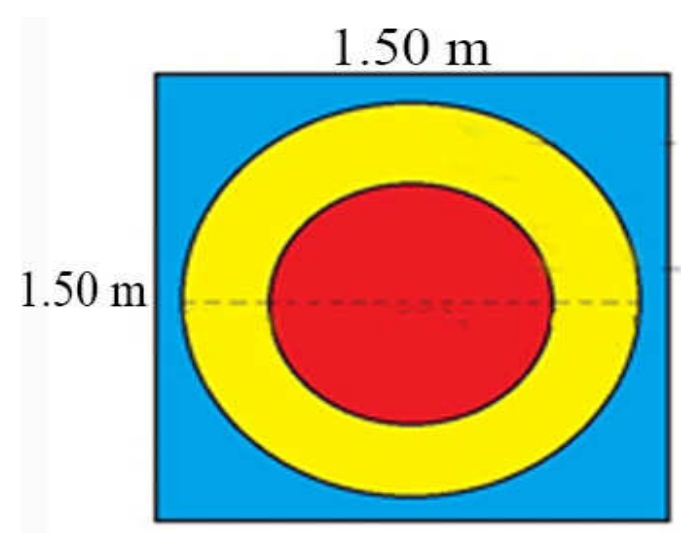

Gambar 2. Desain Alat Tampak Depan

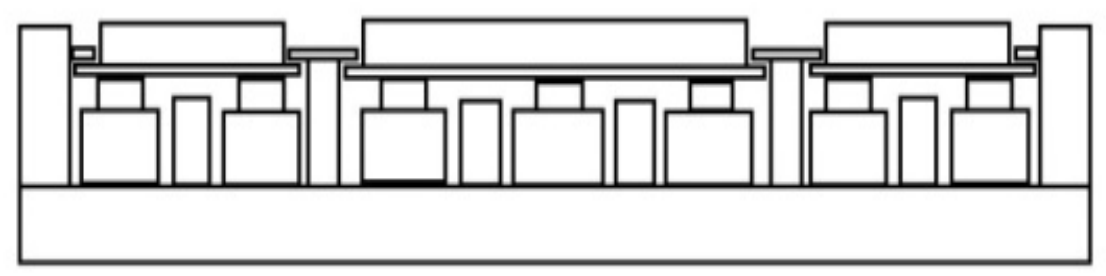

Gambar 3. Desain Komponen Sensor Pada Alat

\section{METODE}

Penelitian ini bertujuan pada sebuah produk yang telah dikembangkan. Penelitian ini menggunakan metode research and development. Langkah-langkah pengembangan produk (Sugiyono, $2018: 409)$ :

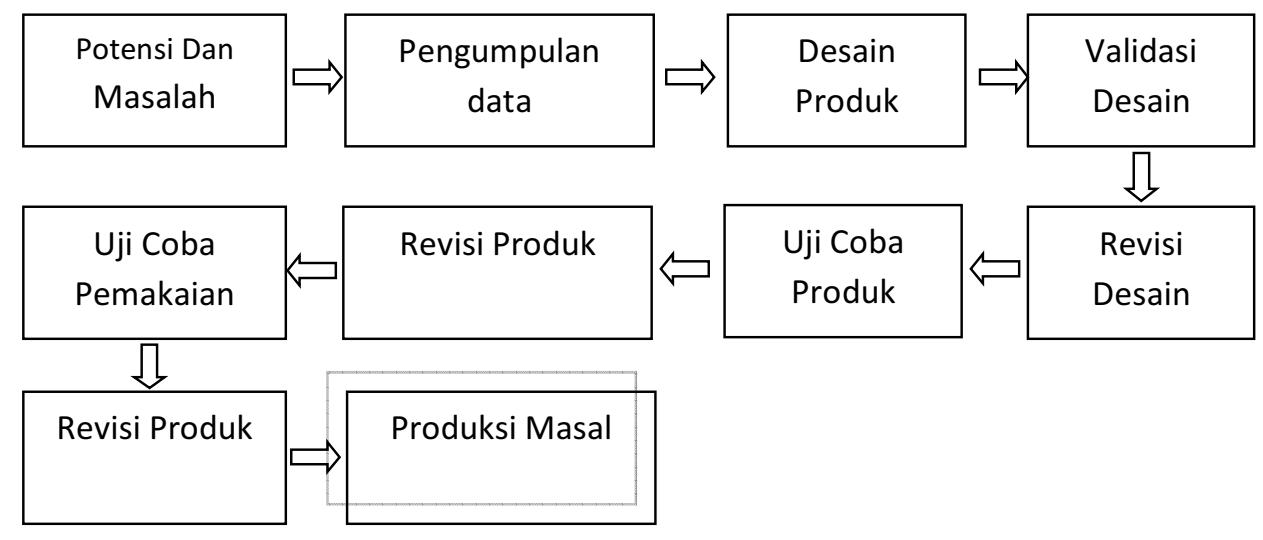

Gambar 4. Langkah Penggunaan Metode Research and Development (Sumber: Sugiyono, 2018 ; 409)

Teknik penentuan subjek uji coba dalam penelitian ini adalah dengan motode purposive sampling. Menurut Suharsimi Arikunto (2004:84) purposive sampling adalah teknik penentuan sampel dengan kreteria yang telah ditentukan. Menurut Sugiyono (2018:193) "Teknik pengumpulan data merupakan langkah yang paling strategis dalam penelitian, karena tujuan utama dari penelitian adalah mendapatkan data". Tanpa mengetahui teknik-teknik pengumpulan data, maka peneliti tidak akan 
mendapatkan data yang memenuhi standar data yang ditetapkan. Adapun instrument yang digunakan dalam penelitian ini dengan menggunakan:

a. Observasi. Observasi adalah pengamatan dan pencatatan yang sistematis terhadap gejala-gejala yang diteliti. Dalam hal ini, peneliti pengawasan dengan cermat setiap perkembangan yang berkaitan dengan pengembangan "PABA" alat latihan teknik dasar bolavoli

b. Kuesioner (Angket). Menurut Sugiyono (2018:1999) kuesioner adalah teknik pengumpulan data yang dilakukan dengan vara member seperangkat pertanyaan atau pernyataan tertulis kepada responden untuk dijawabnya. Kuesioner merupakan teknik pengumpulan data yang efisien bila peneliti tahu dengan pasti variabel yang akan diukur dan tahu apa yang bisa diharapkan dari responden.

c. Dokumentasi. Berisi lampiran-lampiran berupa tulisan, foto, gambar-gambar serta hal-hal yang memungkinkan untuk digali sebagai data dalam proses penelitian dan menggunakan library reseach, seperti Buku-buku, Jurnal-jurnal Ilmiah baik jurnal internasional maupun jurnal nasional, skripsi/tesis, Undang-Undang dan sumber-sumber lain yang mendukung untuk membuat suatu instrument. Menurut Sugiyono (2018:173) instrumen dikatakan valid bila alat ukur yang digunakan dapat mengukur data valid. Agar penelitian pengembangan alat ini valid, maka peneliti menambahkan angket dimana ahli materi dan ahli media mengisi sesuai dengan pertanyaan yang disediakan. Validasi instrument untuk ahli materi dan ahli media dilakukan melalui konsultasi dan meminta penilaian kepada para ahli yang memiliki keahlian tentang materi yang akan diuji dan kreteria media pembelajaran.

Menurut Bogdan dalam Sugiyono (2018:244) Analisis data adalah proses mencari dan menyusun secara sistematis data yang diperoleh dari hasil wawancara, catatan lapangan, dan bahanbahan lain, sehingga dapat mudah dipahami, dan temuannya dapat diinformasikan kepada orang lain. Analisis data dilakukan dengan mengorganisasikan data, menjabarkannya ke dalam unit-unit, melakukan sintesa, menyusun ke dalam pola, memilih mana yang penting dan yang akan dipelajari, dan membuat kesimpulan yang dapat diceritakan kepada orang lain. Pada penelitian pengembangan ini teknik analisis data digunakan dengan teknik analisa deksriptif kuantitatif dengan persentase. Teknik ini digunakan agar mendapat analisa data kuantitatif yang didapatkan dari penyebaran angket.

Konsistensi hasil yang ditunjukan oleh alat diuji dengan uji reliabilitas dengan cara dilakukan uji coba oleh beberapa orang atlet secara berulang-ulang. Untuk menghitung reabilitas digunakan rumus korelasi product moment dengan mengkorelasikan hasil tes (test re-test).

Pengembangan alat pelontar bola multifungsi divalidasi oleh para ahli dibidangnya, yaitu seorang ahli materi, ahli media dan ahli materi olahraga kepelatihan. Tinjauan para ahli menghasilkan penilaian dalam ujicoba produk produk sebagai berikut:

\section{Persentase}

\begin{tabular}{|c|c|c|c|}
\hline & & & \\
\hline $\begin{array}{l}90,00 \% \\
80,00 \%\end{array}$ & & & \\
\hline & Ahli Materi & Pelatih & Ahli Media \\
\hline - Persentase & $85,80 \%$ & $89,20 \%$ & $97,90 \%$ \\
\hline
\end{tabular}

\section{Gambar 5. Persentase Penilaian Pada Ujicoba Produk}

Nilai rata-rata dari ketiga ahli yaitu ahli materi, pelatih dan ahli media adalah 90,96\%. Sehingga dapat dikategorikan sebagai layak dan dapat digunakan. 

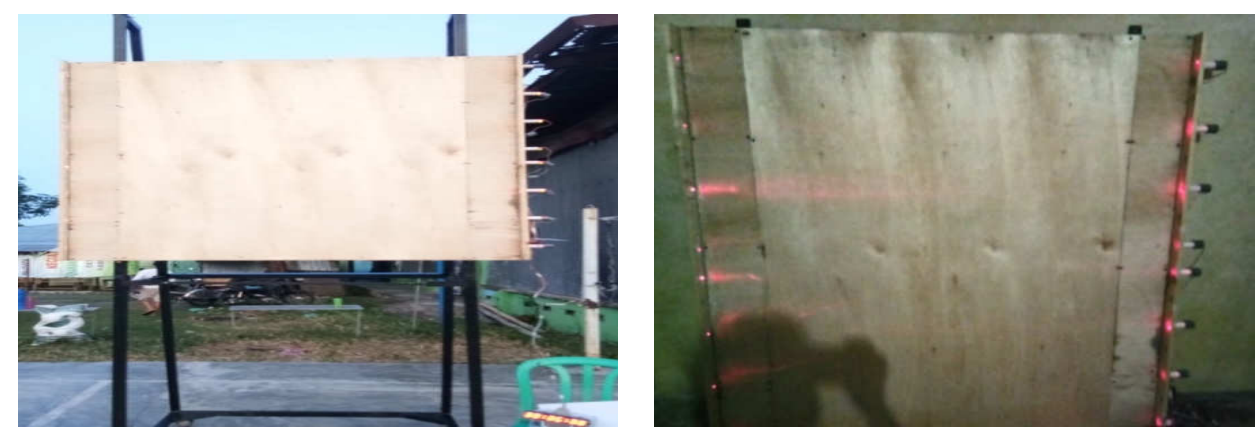

Gambar 6. Alat Tampak Depan Pada Ujicoba Produk
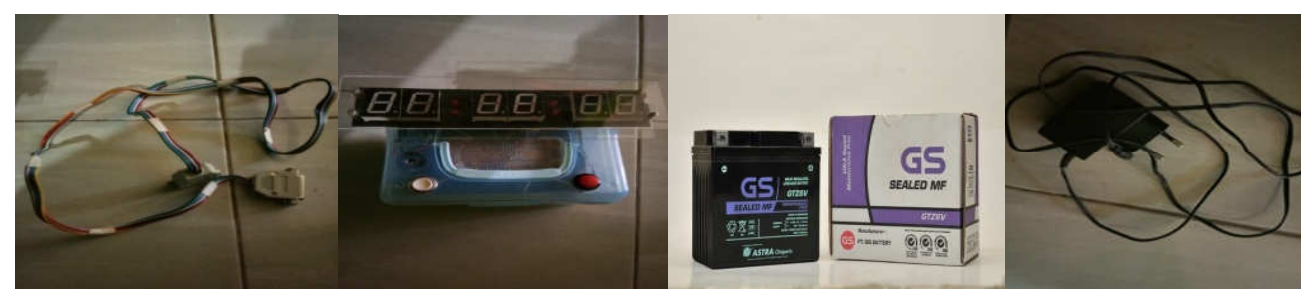

Gambar 7. Komponen Elektronik Pada Alat (Kabel batrai ke laser, Timer, Baterai, Adaptor Charger)

Pengembangan alat pelontar bola multifumgsi divalidasi oleh para ahli dibidangnya, yaitu seorang ahli materi, ahli media dan ahli materi olahraga kepelatihan. Tinjauan para ahli menghasilkan penilaian dalam ujicoba produk pemakaian sebagai berikut:

\section{Persentase}

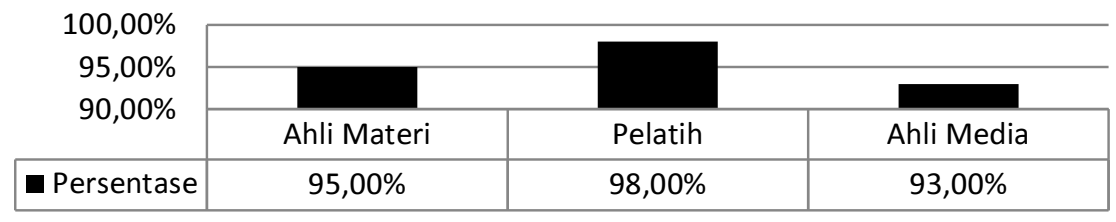

Gambar 8. Persentase Penilaian Pada Ujicoba Pemakaian

Nilai rata-rata dari ketiga ahli yaitu ahli materi, pelatih dan ahli media adalah 95,33\%. Sehingga dapat dikategorikan sebagai layak dan dapat digunakan.
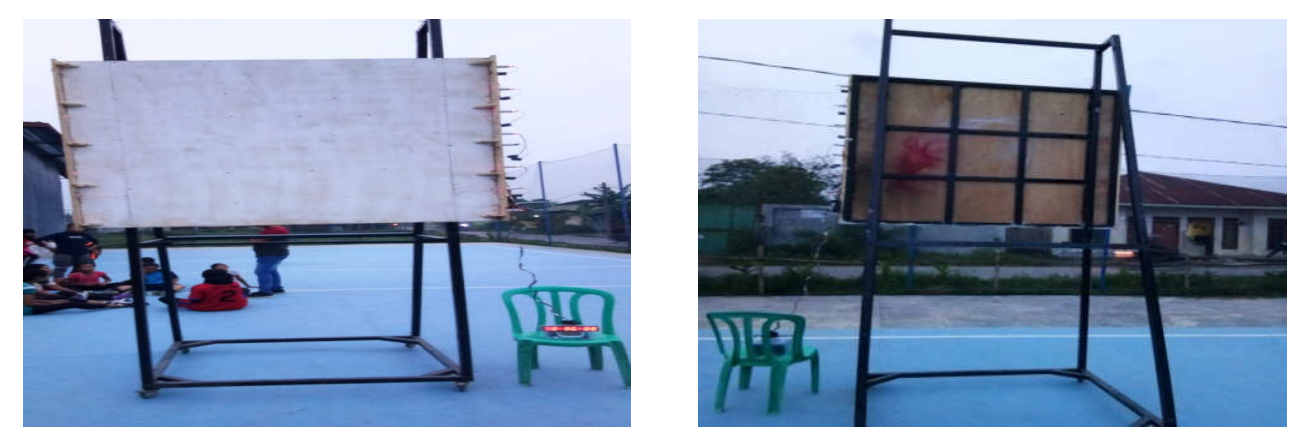

Gambar 9. Alat Tampak Depan dan Belakang Pada Ujicoba Pemakaian 
Alat tes passing atas dan passing bawah bolavoli ini dikalibrasi dengan ditentukannya norma tes sebagai pedoman atlet dalam mengukur kemampuan passingnya dengan cara menghitung validitas dan reliabilitas alat kemudia dihasilkannya norma tes sebagai berikut.

Tabel 1. Norma Tes Passing Atas

\begin{tabular}{lc}
\hline \multicolumn{1}{c}{ Kategori } & Skor \\
\hline Baik Sekali & $>36$ \\
\hline Baik & $34-36$ \\
\hline Sedang & $32-33$ \\
\hline Kurang & $28-31$ \\
\hline Kurang Sekali & $<28$ \\
\hline
\end{tabular}

Tabel 2. Norma Tes Passing Bawah

\begin{tabular}{lc}
\hline \multicolumn{1}{c}{ Kategori } & Skor \\
\hline Baik Sekali & $>36$ \\
\hline Baik & $34-36$ \\
\hline Sedang & $32-33$ \\
\hline Kurang & $29-31$ \\
\hline Kurang Sekali & $<29$ \\
\hline
\end{tabular}

\section{SIMPULAN}

Setelah mengetahui hasil dari rata rata nilai baik dari kelompok kecil dan kelompok besar maka dapat dikatakan pengembangan instrumen tes passing bolavoli berbasis digital sebagai media pelatihan teknik dasar bolavoli dianggap layak. Alat ini juga dapat membantu pelatih dalam variasi latihan teknik dasar bolavoli sesuai kebutuhan serta melalui menggunakan alat papan pantul ini latihan teknik dasar bolavoli lebih mudah dilakukan dengan memakai luas lapangan hanya $3 \times 5$ meter. Menurut hasil perhitungan uji reliabilitas diatas maka dapat disimpulkan bahwa tes passing bolavoli ini reliabel karena memiliki hasil yang konsisten disetiap tes yang dilakukan.

Setelah melalui beberapa tahapan pengembangan instrumen tes passing bolavoli berbasis digital sebagai media pelatihan teknik dasar, maka penelian ini dapat disimpulkan sebagai berikut: (1) Terciptanya pengembangan instrumen tes passing bolavoli berbasis digital sebagai media kepelatihan bolavoli dengan spesifikasi; (2) Kerangka awal dapat berupa papan pantul yang terbuat dari triplek; (3) Kerangka terbuat dari besi; (4) Alat di sertai dengan lesser untuk menghitung berapa kali pantulan bolavoli dilakukan atlet. Produk layak digunakan dari aspek fisik, desain dan penggunaa baik ketahanan dan kepraktisan alat terhadap cuaca dan pantulan bola

\section{DAFTAR PUSTAKA}

Andang Ismail. (2006). Education Games. Yogyakarta: Pilar Medai.

Sadiman Arif S. (2003). Media Pendidikan Pengertian, pengembangan dan Pemanfaatannya. Jakarta. Pustekom Dikbud 
Bompa, Tudor O. (1983). Theory and Methodology of Training to Key Athletic Performance. Canada Kendal: Hunt Publishing Company.

Meelke Danny. (2003). Soccer Fundamentals. United States: Human Kinetics Publishers.

M. Sajoto (1995). Pembinaan Kondisi Fisik Dalam Olahraga. Semarang: IKIP Semarang Press.

Sukmadinata, Nana Syaodih. (2010). Metode Penelitian Pendidikan, Bandung : PPS UPI.

Sugiyono. (2008). Metode Penelitian Kuantitatif, Kualitatif dan $R \&$ D. Bandung: Alfabeta.

Sue Bredekamp. (1987). Developmentally Appropriate Practice in Early Chilhood Program Serving ChildrenFrom Birth Throught Age 8 (Washington: NAYC.

Nugroho, Erfiyanto Dwi. (2016). Pengembangan Alat Plontar Bola Multifungsi. Dalam jurnal Pendidikan Kepelatihan Olahraga. $P d f$.

Siskawati, Maya, dkk. (2016). Pengembangan media pembelajaran bolavoli untuk meningkatkan belajar geografi siswa. Dalam jurnal Studi sosial vol.4, No.1. Pdf.

Wibisono, Rezeki. (2015). Pengaruh Penerapan Modifikasi Smesh Bolavoli Terhadap Hasil Belajar Gerak Dasar Smesh Bolavoli (studi pada siswa kelas Xi IPA3 SMA NEGERI 1 PRAJEKAN KABUPETEN BONDOWONGSO). Dalam jurnal Pendidikan Olahraga dan Kesehatan Vol.3, No.01 hal 25-28. $P d f$.

Yusmar, Ali. (2017). Upaya Peningkatan Teknik Permainan Bolavoli Melalui Modifikasi Permainan Siswa Kelas X SMA NEGERI 2 KAMPAR. Dalam jurnal Pendidikan dan pengajaran program studi pendidikan guru sekolah dasar FKIP Universitas Riau, Vol.1, No.1 Juli. Pdf 